\title{
Maternal Early Life Factors Associated with Hormone Levels and the Risk of Having a Child with an Autism Spectrum Disorder in the Nurses Health Study II
}

\author{
Kristen Lyall, \\ Department of Epidemiology, Harvard School of Public Health, Boston, MA, USA \\ David L. Pauls, \\ Department of Epidemiology, Harvard School of Public Health, Boston, MA, USA; Department of \\ Psychiatry, Harvard Medical School, Boston, MA, USA; The Neurodevelopmental Genetics Unit, \\ Center for Human Genetic Research, Massachusetts General Hospital, Boston, MA, USA

\section{Susan Santangelo,} \\ Department of Epidemiology, Harvard School of Public Health, Boston, MA, USA; Department of \\ Psychiatry, Harvard Medical School, Boston, MA, USA; The Neurodevelopmental Genetics Unit, \\ Center for Human Genetic Research, Massachusetts General Hospital, Boston, MA, USA \\ Donna Spiegelman, and \\ Departments of Epidemiology and Biostatistics, San Francisco, CA, USA

\section{Alberto Ascherio \\ Departments of Epidemiology and Nutrition, Harvard School of Public Health, 655 Huntington Ave, Building II 3rd Floor, Boston, MA 02115, USA; Channing Laboratory, Department of Medicine, The Brigham and Women's Hospital and Harvard Medical School, Boston, MA, USA}

\section{Abstract}

It is not known whether reproductive factors early in the mother's life influence risk of autism spectrum disorders (ASD). We assessed maternal age at menarche, menstrual cycle characteristics during adolescence, oral contraceptive use prior to first birth, body shape, and body mass index (BMI) in association with ASD using binomial regression in a cohort study of 61,596 women, including 743 cases. Overall, early life factors were not associated with ASD, though early age at menarche (RR for age 10 or less $=1.54,95 \%$ CI 1.18, 2.02, $p=0.0002$ ) and BMI at age 18 of $\geq 30$ (RR 2.03, 95\% CI 1.34, 3.08, $p=0.0008$ ) were significantly associated with increased risk of ASD. Further work should investigate the potential influence of these factors.

\section{Keywords}

Autism spectrum disorders; Reproductive risk factors; Hormonal factors

While there is extensive literature assessing the association between autism and pre- and perinatal factors, other maternal reproductive factors, including those of the mother's early life, have rarely been investigated. Some of these factors, such as maternal age at menarche,

(C) Springer Science+Business Media, LLC 2010

klyall@hsph.harvard.edu.

Conflicts of interest

No conflicts of interest are noted. 
menstrual cycle regularity and length, and obesity, are related to endogenous hormonal levels and have been associated with breast cancer and psychosocial difficulties (Terry et al. 2005; Golub et al. 2008), and may, directly or indirectly, influence pregnancy outcomes. Previous work has demonstrated a moderate correlation between maternal and fetal hormone concentrations (Troisi et al. 2003); further, maternal testosterone levels have been associated with offspring outcomes ranging from birth weight (Carlsen et al. 2006) to sex-specific behaviors (Hines 2006; van de Beek et al. 2009). Although the claim remains controversial, fetal testosterone levels have been hypothesized to be related to risk of autism, especially as one study demonstrated a positive association between testosterone measured from amniotic fluid and a measure of autistic characteristics (Baron-Cohen et al. 2004). If this association holds and extends to maternal testosterone levels, then assessment of maternal BMI may be of interest, as testosterone levels have been found to be related to BMI in women (Tworoger et al. 2006; Zhang et al. 2007). In addition to influencing hormone levels, early life factors such as abnormal menstrual characteristics could be a marker for broader reproductive health problems in mothers of children with ASD, and thus could at least partially explain the commonly noted association between obstetric complications and autism spectrum disorders (ASD) (Bolton et al. 1997; Brimacombe et al. 2007).

We studied the hypothesis that early life factors related to maternal hormonal levels are associated with the risk of having a child with an ASD in the Nurses' Health Study II, a large prospective investigation among US women. Because pre-gravid use of oral contraceptives (OC) has been associated with fetal growth (Mucci et al. 2004) and twin births (Rothman 1977), suggesting that a hormonal influence can persist after discontinuation, we also examined the relation between OC use prior to first birth and risk of having a child with ASD.

\section{Methods}

\section{Participants}

The study population is comprised of participants in the Nurses' Health Study II (NHS II), a prospective cohort of 116,608 female nurses aged 25-43 when recruited in 1989 and followed by biennial mailed questionnaires to assess the incidence of cancer and other chronic diseases. The 2005 questionnaire included an item asking women if they have a child diagnosed with any of the following diseases: (1) autism, Asperger's syndrome, or other autism spectrum disorder; (2) attention-deficit hyperactivity disorder (ADHD); (3) epilepsy; (4) multiple sclerosis; or (5) diabetes. Only women who responded to the 2005 questionnaire and have at least one birth reported were eligible for this study (adopted children were not included). In order to allow time for diagnosis as reported on the 2005 questionnaire, children must have been born by the end of 2003. About 81,393 women responded to the 2005 questionnaire; 66,445 of those women had at least one child by the end of 2003. We further excluded women with missing data on any of the primary exposures of interest, which were all assessed in 1989 at the start of the NHS II (baseline): age at menarche, menstrual cycle regularity during high school, menstrual cycle length at age 1822 , time until cycle regularity, body shape at age 10, body mass index (BMI) at age 18 and at baseline, and oral contraceptive use and duration of use prior to first pregnancy. 50 cases (6.3\% of mothers reporting a child with an ASD) and 4,799 non-cases (7.3\% of mothers of healthy children) were missing at least one primary exposure variable. For the purposes of sensitivity analyses, we created a prospective sub-group of women who met these prior exclusions but further excluded the 53,098 women with first births prior to 1989 , in order to ensure that exposures were reported and measured prior to first birth. 


\section{Case Definition}

Cases were defined as those women meeting inclusion criteria described above and reporting having had a child with autism, Asperger syndrome, or other autism spectrum disorder on the 2005 questionnaire. If this particular item was left blank but the rest of the questionnaire was completed, it was assumed the mother had no ASD affected children. No further information on the affected child was available. Two Center for Disease Control and Prevention (CDC) studies have utilized parental report of ASD, and a high concordance in estimated prevalence of ASD between the two studies was seen, as was a strong correlation between report of diagnosis and developmental and behavioral problems as measured on screening items (CDC 2006); the reader is referred to that CDC report for a further discussion of the validity of parental report of ASD diagnoses.

\section{Exposure Information}

All of the primary exposures under study were assessed at baseline; oral contraceptive use and information on body weight were also updated on every questionnaire. Body mass index was calculated as weight divided by height in meters squared from weight and height information provided at baseline. Previous validation studies of self-reported weight in this cohort have been conducted $(r=0.87)$ (Troy et al. 1995). Body shape at age 10 was assessed on the 1989 questionnaire utilizing a diagram which has been previously validated against height and weight measurements (Pearson correlation $=0.65$, Spearman correlation $=0.70$ ) and has been utilized in other studies (Must, Willett, and Dietz 1993; Tworoger et al.2006). All NHS II questionnaires are available online at http://www.channing.harvard.edu/nhs/ questionnaires/index. shtml.

\section{Statistical Analyses}

Our study included women from the NHS II at risk for having a child with an ASD by the end of 2003. Univariate relationships and basic characteristics of menstrual cycle, body shape, BMI, and OC use were assessed by descriptive statistics, $\chi^{2}$ tests, and $t$-tests. Risk ratios for the relation between ASD and early reproductive factors, with and without adjustment for potential confounders, were calculated using log-binomial regression (Wacholder 1986; Spiegelman and Hertzmark 2005). Potential confounders considered included the nurses' age in years at baseline, race (as a binary indicator for white or other), income level (in five categories of household income), and, for certain analyses, the nurses' age at menarche (in years from 9 or less through 17 or greater). For age at menarche, BMI, andbody shape, the median category was used as the referent. When assessing menstrual cycle regularity in high school, an indicator was used for the 215 individuals reporting no periods (results not shown for this category but were non-significant). The ordinal score test was used to assess evidence for a trend in non-binary variables. We also tested for nonlinearity in the relation between BMI and ASD non-parametrically with cubic splines (Durrleman and Simon 1989; Govindarajulu et al. 2007). For purposes of comparison to the literature, we chose to use a priori categorizations of variables that have been used in other studies (Tworoger et al. 2006; Feskanich et al. 2008) and that adequately captured the distribution with our population.

In order to eliminate the potential for recall bias, as may occur, for example, if a woman with a child with an ASD provided more complete information on menstrual cycle or other exposures of interest, we also conducted all analyses restricted to women who had their first child after 1988, which is after collection of the information on the exposures of interest. 8,498 women were included in this prospective sub-group. 


\section{Results}

743 cases and 60,853 non-cases were included in our primary analyses. 221 cases and 8,277 non-cases were included in the prospective sub-group in which exposure had to have been assessed prospectively before the outcome. Characteristics of the study population are shown in Table 1.

Overall, distributions of the factors under study were similar between the cases and noncases. In crude comparisons in the full study, cases were more likely to have had an early age at menarche, a longer time until cycle regularity, a longer duration of pregravid OC use in years, and a higher BMI at age 18, though only the OC duration association was significant $(p<0.05)$. These crude comparisons were similar in the prospective sub-group, though the OC duration association was reversed, with longer duration among non-cases.

Results for the full study are shown in Table 2. Age at menarche of 10 or less was significantly associated with an approximately $60 \%$ increased risk of ASD $(p=0.002)$, while age of menarche of 11 was associated with an approximately $30 \%$ increased risk of $\operatorname{ASD}(p=0.03)$. Other menstrual cycle variables, as well as variables assessing OC use, were not associated with ASD risk. BMI of 30 or greater at age 18 was the only other factor significantly associated with risk of ASD in the full study $(p=0.0008)$, indicating a doubling in risk. Fully adjusted results were materially unchanged when the potential confounders income and age at menarche (when not being assessed as a primary exposure) were excluded from the models.

The association with high BMI at age 18 remained significant $(p=0.0003)$ in the prospective sub-group as well (Table 3). BMI reported at 1989 was not associated with ASD in either the full study or prospective group. Further, the significant association seen with early age at menarche in the full study was not replicated in the pro-spective sub-group. We did find a marginally significant protective association with pregravid OC use of $\geq 3$ years in the prospective group, though this association was not found in the full study.

In the full study, tests for linear trend were non-significant for all factors, though the ordinal score test of trend was significant for age at menarche only $(p=0.03)$. BMI at age 18 was the only variable that had a significantly non-linear association with ASD risk $(p=0.008)$. The plot of BMI at 18 in relation to ASD risk is shown in Fig. 1. In the prospective subgroup, tests for trend and non-linearity were non-significant for all factors.

Finally, because of relationships between age at menarche, BMI, and gestational diabetes (Laitinen et al. 2001; Harris et al. 2008; Torloni et al. 2009), and the suggestion of gestational diabetes as a risk factor for ASD in a number of studies (Gardener et al. 2009; Lyall et al. 2009), we tested whether the associations seen with BMI and age at menarche could be accounted for by gestational diabetes by including report of gestational diabetes during first pregnancy in multivariate adjusted models. Results remained materially unchanged for age at menarche and were somewhat weaker but still significant for BMI at 18 for both the full study and prospective sub-group (adjusted RR for BMI $\geq 30$ in full study $=1.94,95 \%$ CI 1.28, 2.93; prospective $\mathrm{RR}=2.70,95 \%$ CI 1.54, 4.74), suggesting these associations cannot be fully explained by a gestational diabetes-mediated pathway. Results also did not change when we examined the effect of additional adjustment for gestational diabetes in the subgroup of women with only 1 child in order to obtain child-specific information. When further adjusting for infertility and ovulation-inducing drug use, factors we have also found to be associated with ASD (Lyall et al. 2010), results also remained materially unchanged. 


\section{Discussion}

This study of maternal early life factors potentially associated with ASD found a significant relationship with maternal late adolescent BMI, indicating an approximate doubling of the risk of having a child with an ASD among individuals with a BMI of 30 or greater at age 18. There was also an increased risk with early menarche (age $\leq 11$ )in the full study but not in the prospective sub-group. Our results suggest that overall, early life maternal menstrual cycle characteristics and OC use do not affect risk of ASD. However, the statistically significant associations we found with early menarche and high BMI at age 18 should be examined in other studies.

The strengths of this study include a large sample size, a geographically representative national sample, a wealth of high quality maternal information, and the ability to assess results in a prospective sub-group. A number of limitations should also be noted. All information utilized in this study is self-reported via mailed questionnaires; therefore miscategorization of menstrual cycle characteristics, OC use, body shape and BMI, and other model covariates is possible. However, this is a sample of nurses, who have previously been shown to provide highly reliable and valid self-reported health information (Colditz et al. 1986; Troy et al. 1995; Colditz et al. 1997; Tomeo et al. 1999). We also do not have diagnostic confirmation on ASD status; only maternal report was available. However, a number of studies have utilized maternally-reported diagnosis of ASD and other child conditions, and have demonstrated reliability of these reports as well as validity with measures of developmental problems (Faraone et al. 1995; CDC 2006); in addition, reporting may be even more accurate in this medically trained population. Misclassification of women who may later have gone on to have a child with an ASD as non-cases is also possible; however, by 2003 the majority of women in the cohort had completed their childbearing years (only $2.7 \%$ of the cohort gave birth after 2000); thus, any such misclassification is expected to be small. Further, the inclusion of borderline ASD cases would tend to weaken rather than strengthen observed associations. While additional information on the affected child, such as date of birth and gender, would be useful in detailed analyses of exposures during and immediately prior to pregnancy, our analyses focused on early life factors and utilized the mother as the case unit (i.e. women who later go on to have a child with an ASD).

Because we focused our analyses on factors occurring early in the mother's life, unmeasured confounding by other maternal factors is unlikely. We did not have information on use of steroid hormones or hormone levels prior to the exposures under study; however, use of steroids would need to occur prior to menarche or age 18 to act as a confounder for the relationships studied here. Genetic factors may be involved in both the development of ASD and the exposures under study; however, this would need to be addressed in a separate study. The potential for recall bias is possible in our full study; however, utilization of the prospective sub-group reduces this concern.

While there has not been extensive research into the potential developmental effects of pregravid OC use on subsequent offspring, the research of Mucci and colleagues suggested that OC use does positively affect birth weight and fetal growth (Mucci et al. 2004). Taken together with the decreased risk of certain cancers among past OC users (Mucci et al. 2004), these results implicate a persistent effect of OCs on hormone levels and suggest that pregravid use is of interest when considering maternal hormonal factors. We did not find an association between maternal use of oral contraceptives prior to first birth and risk of having a child with ASD; nor was longer duration of use associated with ASD in our full study. These results are consistent with one study that found no association between maternal OC use and ASD (Torrey et al. 1975), and are in line with the overall findings of the safety of 
OC use with regard to child health (Rothman 1977; Vessey et al. 1979). Our result in the prospective sub-group of a somewhat decreased risk associated with longer duration of OC use just reached significance and could be due to chance, but needs to be assessed further in other studies. One small retrospective case control study found significantly less use of oral contraceptives in cases compared to controls (Juul-Dam et al. 2001), which is contradictory to our prospective group finding; it is possible that differences in timing of use or sample size across studies may account for the discrepancy.

Our results suggest that maternal menstrual cycle characteristics earlier in life such as length and regularity do not have a role in the development of ASD. However, we did see a significant relationship between early age at menarche in the full study but not prospective group. There is evidence to suggest that the average age at menarche in the USA has decreased, while the prevalence of ASD has increased over the past few decades (Fombonne 2005; Golub et al. 2008). Adjustment of the estimated effects for age should account for any confounding due to these secular trends. The lack of consistency of this association in the prospective sub-group could be due to the fact that statistical power to detect the moderate association was somewhat reduced with the smaller case size (70\% in the prospective subgroup to detect OR of 2 comparing top category to lowest vs $99 \%$ in the full study) (Chapman and Nam 1968), or possibly residual confounding in the full study.

This is the first study to suggest that there may be an association between maternal late adolescent BMI and risk of having a child with ASD. We found nearly a doubling of the risk associated with obesity at age 18 , and this association was also observed in the full cohort with an additional measure of body fatness, a body shape diagram ("Appendix"), at age 20 (data not shown). However, we did not find a significant association with BMI at baseline, either in the full or the prospective sub-group. Nor does it appear that the association with BMI or body fatness extends to very early in the mother's life, as we assessed as early as the nurses' birthweight (data not shown) and body shape at age 10, and no significant associations were seen with these factors. While the BMI at 18 result could be due to chance, the consistency of the association in our full study and prospective sub-group supports the finding, and future work should investigate the role of maternal late adolescent BMI in association with ASD.

Maternal BMI itself has not, as of this writing, been directly studied in association with ASD, although one previous study assessed maternal morphology during pregnancy and identified a positive association between both maternal weight and height and having a child with autism (Wilkerson et al. 2002). Our results suggest that late adolescent/early adulthood obesity, rather than BMI at a closer time to pregnancy with the affected child, may increase risk of ASD. Such an association could be due to longer-term effects of obesity beginning earlier in life which may have an impact on hormone levels, reproductive processes, or the perinatal environment.

Overall, our results do not support the hypothesis that underlying maternal hormone levels prior to pregnancy have a strong effect on risk of ASD. However, certain factors, such as BMI or menarche, may influence risk through a hormonal pathway. The potential effect of early age at menarche found in our full study could lend support to an altered hormone profile; however, as discussed, the lack of consistency of this result in the prospective subgroup limits the strength of the observed association. Our findings regarding BMI at age 18 could also be due to a hormonally-mediated pathway. There is evidence in other fields to suggest that differing hormone profiles can have a lasting effect on disease risk. Specifically, individuals who develop breast cancer may be exposed to different hormone levels than those who do not, as suggested by both direct analyses of hormone levels and associations with BMI and body shape (Carmichael and Bates 2004; Tworoger et al.2006). Among 
women in this cohort, adult and adolescent BMI has been inversely associated with risk of breast cancer, which has been suggested to be due to a hormonally-mediated pathway (Baer et al. 2005; Tworoger et al.2006). Further, in a study of 592 premenopausal NHS II participants, aged 33-52 years old, a positive association has been found between BMI at age 18 and in adulthood and free testosterone levels (Tworoger et al. 2006). This study measured plasma concentrations of hormone levels from timed follicular and luteal phase blood samples in order to measure levels of sex hormones-including testosterone, estradiol, and progesterone-as compared to BMI, waist-to-hip ratio, and body shape. However, the study only assessed hormone levels at one time point; further work is needed to determine whether body mass is consistently related to hormone levels over time. Further, given the association Tworoger and colleagues found between BMI in adulthood and hormone levels, future work should also further investigate maternal adult BMI despite our null finding for BMI at baseline.

Other factors not available here, such as maternal psychiatric history, could potentially confound the BMI relationship; in particular, obesity has been linked with depression (Mather et al. 2009), which has also been found to be elevated in parents of children with ASD (Larsson et al. 2005; Lauritsen et al. 2005). While we do not have information on maternal depression history at age 18 , information on antidepressant medications was collected in later questionnaire years (1993, 1997, 2001 and 2003), although the diagnosis of clinical depression was not assessed until 2003. Depression in any of these postbaseline years could be related to depression at age 18 , since depression commonly reoccurs throughout the lifespan (Bos et al. 2005). However, adjustment for reporting of depression or antidepressant use in any of these years did not significantly alter the association. Future work investigating maternal BMI should also include more detailed psychiatric information.

Autism is known to have strong genetic influences; however, there is research suggesting that fetal development may play a role in the expression of ASD (London and Etzel 2000). We were interested in determining whether factors extending even earlier than pregnancy in the mother's life may be involved. Our results suggest that many early life maternal reproductive factors, including menstrual cycle length and regularity, body shape in childhood, and pre-gravid OC use, do not influence the risk of having a child with an ASD, but that maternal age at menarche and late adolescent BMI may be associated with ASD in the offspring. Further work will be needed to determine the consistency and nature of the potential associations between maternal early menarche, late adolescent BMI, and risk of having a child with ASD. If these associations do hold in other studies, it would be suggestive of a role for maternal hormones in risk of having a child with autism.

\section{Acknowledgments}

The Nurses' Health Study II is an ongoing study conducted at the Channing Laboratory and affiliated with the Brigham and Women's Hospital, Harvard School of Public Health, and Harvard Medical School. The work reported in this manuscript was funded in part by CA50385, the main Nurses' Health Study II grant, 1788 from the Autism Speaks Foundation, and A-14917 from the U.S. Army Medical Research and Material Command (USAMRMC). The funding organizations have reviewed and approved the design and conduct of the overall NHS II, but were not involved in the collection, management, analysis, or interpretation of the data; nor were they involved in the preparation, review, or approval of this manuscript.

\section{Appendix}

Diagram used for estimating body shape at age 10 


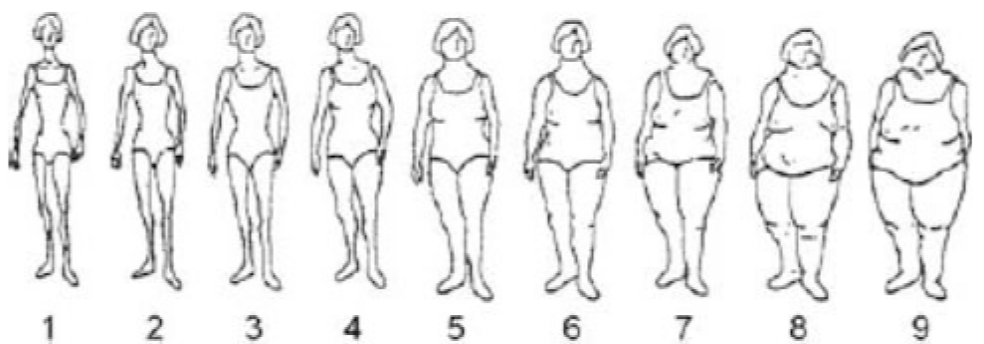

\section{References}

Baer H, Colditz GA, Rosner B, Michels KB, Rich-Edwards JW, Hunter DJ, et al. Body fatness during childhood and adolescence and incidence of breast cancer in premenopausal women: A prospective cohort study. Breast Cancer Research. 2005; 7(3):R314-R325. [PubMed: 15987426]

Baron-Cohen, S.; Lutchmaya, S.; Knickmeyer, R. Prenatal testosterone in mind. MIT Press; Cambridge: 2004.

Bolton PF, Murphy M, MacDonald H, Whitlock B, Pickles A, Rutter M. Obstetric complications in autism: Consequences or causes of the condition? Journal of the American Academy of Child and Adolescent Psychiatry. 1997; 36(2):272-281. [PubMed: 9031581]

Bos EH, Bouhuys AL, Geerts E, Van Os TW, Van der Spoel ID, Brouwer WH, et al. Cognitive, physiological, and personality correlates of recurrence of depression. Journal of Affective Disorders. 2005; 87(2-3):221-229. [PubMed: 15979155]

Brimacombe M, Ming X, Lamendola M. Prenatal and birth complications in autism. Maternal and Child Health Journal. 2007; 11:73-79. [PubMed: 17053965]

Carlsen S, Jacobsen G, Romundstad P. Maternal testosterone levels during pregnancy are associated with offspring size at birth. European Journal of Endocrinology. 2006; 155(2):365-370. [PubMed: 16868152]

Carmichael AR, Bates T. Obesity and breast cancer: A review of the literature. Breast. 2004; 13:8592. [PubMed: 15019686]

CDC. Mental health in the United States: parental report of diagnosed autism in children aged 4-17 years-United States, 2003-2004. Mmwr. Morbidity and Mortality Weekly Report. 2006; 55(17): 481-486. [PubMed: 16675944]

Chapman D, Nam JM. Asymptotic power of chi square tests for linear trends in proportions. Biometrics. 1968; 24:315-327. [PubMed: 5683872]

Colditz GA, Manson JE, Hankinson SE. The Nurses' Health Study: 20-year contribution to the understanding of health among women. Journal of Womens Health. 1997; 6(1):49-62.

Colditz G, Martin P, Stampfer MJ, Willett WC, Sampson L, Rosner B, et al. Validation of questionnaire information on risk factors and disease outcomes in a prospective cohort study of women. American Journal of Epidemiology. 1986; 123(5):894-900. [PubMed: 3962971]

Durrleman S, Simon R. Flexible regression models with cubic splines. Statistics in Medicine. 1989; 8:551-561. [PubMed: 2657958]

Faraone SV, Biederman J, Milberger S. How reliable are maternal reports of their children's psychopathology? One-year recall of psychiatric diagnoses of ADHD children. Journal of the American Academy of Child and Adolescent Psychiatry. 1995; 34(8):1001-1008. [PubMed: 7665438]

Feskanich D, Cho E, Schaumberg DA, Colditz GA, Hankinson SE. Menopausal and reproductive factors and risk of age-related macular degeneration. Archives of Ophthalmology. 2008; 126(4): 519-524. [PubMed: 18413522]

Fombonne E. The changing epidemiology of autism. Journal of Applied Research in Intellectual Disabilities. 2005; 18:281-294.

Gardener H, Spiegelman D, Buka S. Prenatal risk factors for autism: Comprehensive meta-analysis. The British Journal of Psychiatry. 2009; 195:7-14. [PubMed: 19567888] 
Golub M, Collman GW, Foster PM, Kimmel CA, Rajpert-De Meyts E, Reiter EO, et al. Public health implications of altered puberty timing. Pediatrics. 2008; 121(Suppl 3):S218-S230. [PubMed: 18245514]

Govindarajulu U, Spiegelman D, Thurston SW, Ganguli B, Eisen EA. Comparing smoothing techniques in Cox models for exposure-response relationships. Statistics in Medicine. 2007; 26(20):3735-3752. [PubMed: 17538974]

Harris M, Prior JC, Koehoorn M. Age at menarche in the Canadian population: Secular trends and relationship to adulthood BMI. Journal of Adolescent Health. 2008; 43(6):548-554. [PubMed: 19027642]

Hines M. Prenatal testosterone and gender-related behaviour. European Journal of Endocrinology. 2006; 155(Suppl 1):S115-S121. [PubMed: 17074984]

Juul-Dam N, Townsend J, Courchesne E. Prenatal, perinatal, and neonatal factors in autism, pervasive developmental disorder-not otherwise specified, and the general population. Pediatrics. 2001; 107(4):E63. [PubMed: 11335784]

Laitinen J, Power C, Järvelin MR. Family social class, maternal body mass index, childhood body mass index, and age at menarche as predictors of adult obesity. American Journal of Clinical Nutrition. 2001; 74(3):287-294. [PubMed: 11522550]

Larsson HJ, Eaton WW, Madsen KM, Vestergaard M, Olesen AV, Agerbo E, et al. Risk factors for autism: perinatal factors, parental psychiatric history, and socioeconomic status. American Journal of Epidemiology. 2005; 161(10):916-925. discussion 926-8. [PubMed: 15870155]

Lauritsen MB, Pedersen CB, Mortensen PB. Effects of familial risk factors and place of birth on the risk of autism: A nationwide register-based study. Journal of Child Psychology and Psychiatry. 2005; 46(9):963-971. [PubMed: 16108999]

London EA, Etzel RA. The environment as an etiologic factor in autism: A new direction for research. Environmental Health Perspectives. 2000; 108(Suppl 3):401-404. [PubMed: 10852835]

Lyall K, Pauls DL, Santangelo S, Speigelman D, Ascherio A. Association between ovulation inducing drug use, infertility, and autism spectrum disorders in the Nurses' Health Study II. Manuscript submitted for publication. 2010

Lyall K, Pauls DL, Speigelman D, Ascherio A, Santangelo S. Pregnancy complications and obstetric suboptimality as risk factors for autism spectrum disorders in children of the Nurses' Health Study II. Manuscript submitted for publication. 2009

Mather A, Cox BJ, Enns MW, Sareen J. Associations of obesity with psychiatric disorders and suicidal behaviors in a nationally representative sample. Journal of Psychosomatic Research. 2009; 66(4): 277-285. [PubMed: 19302884]

Mucci LA, Lagiou P, Hsieh CC, Tamimi R, Hellerstein S, Vatten L, et al. A prospective study of pregravid oral contraceptive use in relation to fetal growth. BJOG: An International Journal of Obstetrics and Gynaecology. 2004; 111(9):989-995. [PubMed: 15327615]

Must A, Willett WC, Dietz WH. Remote recall of childhood height, weight, and body build by elderly subjects. American Journal of Epidemiology. 1993; 138:56-64. [PubMed: 8333427]

Rothman KJ. Fetal loss, twinning and birth weight after oral contraceptive use. New England Journal of Medicine. 1977; 297:468-471. [PubMed: 887128]

Spiegelman D, Hertzmark E. Easy SAS calculations for risk or prevalence ratios and differences. American Journal of Epidemiology. 2005; 162(3):199-200. [PubMed: 15987728]

Terry K, Willett WC, Rich-Edwards JW, Hunter DJ, Michels KB. Menstrual cycle characteristics and incidence of premenopausal breast cancer. Cancer Epidemiology, Biomarkers and Prevention. 2005; 14(6):1509-1513.

Tomeo CA, Rich-Edwards JW, Michels KB, Berkey CS, Hunter DJ, Frazier AL, et al. Reproducibility and validity of maternal recall of pregnancy-related events. Epidemiology. 1999; 10(6):774-777. [PubMed: 10535796]

Torloni M, Betrán AP, Horta BL, Nakamura MU, Atallah AN, Moron AF, et al. Prepregnancy BMI and the risk of gestational diabetes: A systematic review of the literature with meta-analysis. Obesity Reviews. 2009; 10(4):487-488. [PubMed: 19413709] 
Torrey E, Hersh SP, McCabe KD. Early childhood psychosis and bleeding during pregnancy. A prospective study of gravid women and their offspring. Journal of Autism and Childhood Schizophrenia. 1975; 5(4):287-297. [PubMed: 1243134]

Troisi R, Potischman N, Roberts JM, Harger G, Markovic N, Cole B, et al. Correlation of serum hormone concentrations in maternal and umbilical cord samples. Cancer Epidemiology, Biomarkers and Prevention. 2003; 12(5):452-456.

Troy LM, Hunter DJ, Manson JE, Colditz GA, Stampfer MJ, Willett WC. The validity of recalled weight among younger women. International Journal of Obesity and Related Metabolic Disorders. 1995; 19(8):570-572. [PubMed: 7489028]

Tworoger S, Eliassen AH, Missmer SA, Baer H, Rich-Edwards J, Michels KB, et al. Birthweight and body size throughout life in relation to sex hormones and prolactin concentrations in premenopausal women. Cancer Epidemiology, Biomarkers and Prevention. 2006; 15(12):24942501.

van de Beek C, van Goozen SH, Buitelaar JK, Cohen-Kettenis PT. Prenatal sex hormones (maternal and amniotic fluid) and gender-related play behavior in 13-month-old Infants. Archives of Sexual Behavior. 2009; 38(1):6-15. [PubMed: 18080735]

Vessey M, Meisler L, Flavel R, Yeates D. Outcome of pregnancy in women using different methods of contraception. British Journal of Obstetrics and Gynaecology. 1979; 86:548-556. [PubMed: 476021]

Wacholder S. Binomial regression in GLIM: Estimating risk ratios and risk differences. American Journal of Epidemiology. 1986; 123(1):174-182. [PubMed: 3509965]

Wilkerson D, Volpe AG, Dean RS, Titus JB. Perinatal complications as predictors of infantile autism. International Journal of Neuroscience. 2002; 112(9):1085-1098. [PubMed: 12487097]

Zhang Y, Graubard BI, Longnecker MP, Stanczyk FZ, Klebanoff MA, McGlynn KA. Maternal hormone levels and perinatal characteristics: Implications for testicular cancer. Annals of Epidemiology. 2007; 17(2):85-92. [PubMed: 16882463] 

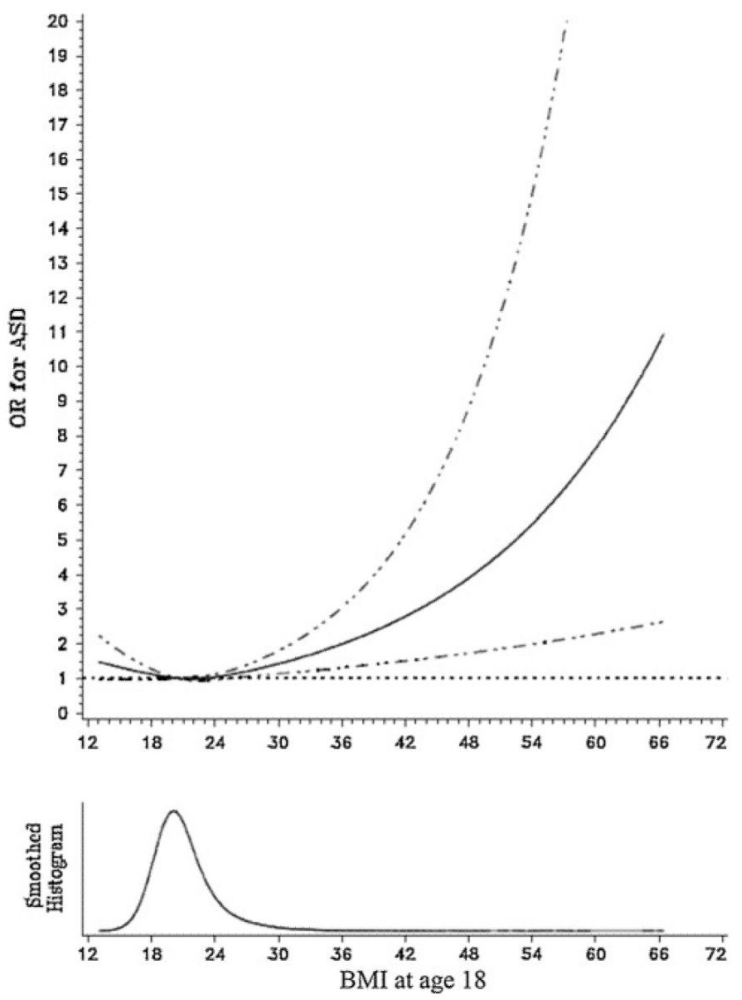

Fig. 1.

Caption: Relation between maternal BMI at age 18 and ASD. The top graph depicts the fully adjusted odds ratio associated with risk of ASD according to value of BMI at age 18 .

Bottom graph depicts the smoothed histogram of BMI at age 18 
Table 1

Distribution of basic characteristics and early life reproductive factors in the study population $(N=61,596)$

\begin{tabular}{|c|c|c|}
\hline Variable & $\begin{array}{l}\text { ASD mothers }(n=743) \\
n(\%) \text { or mean }(\text { std })\end{array}$ & $\begin{array}{c}\text { Non-ASD mothers }(n=60,853) \\
n(\%) \text { or mean }(\text { std })\end{array}$ \\
\hline \multicolumn{3}{|l|}{ Age at baseline } \\
\hline $24-29$ & $221(29.7 \%)$ & $10138(16.7 \%)$ \\
\hline $30-35$ & $291(39.2 \%)$ & $19230(31.6 \%)$ \\
\hline $36-42$ & $58(7.8 \%)$ & $11221(18.4 \%)$ \\
\hline \multicolumn{3}{|l|}{ Race } \\
\hline Caucasian & $695(93.5 \%)$ & $56925(93.6 \%)$ \\
\hline African American & $7(0.9 \%)$ & $689(1.1 \%)$ \\
\hline Other & $34(4.6 \%)$ & $2316(3.8 \%)$ \\
\hline Missing & $7(0.9 \%)$ & $923(1.5 \%)$ \\
\hline \multicolumn{3}{|l|}{ Household income } \\
\hline$<40,000$ & $34(4.6 \%)$ & $2911(4.8 \%)$ \\
\hline $40-74,000$ & $194(26.1 \%)$ & $16020(26.3 \%)$ \\
\hline $75-99,000$ & $131(17.6 \%)$ & $10131(16.7 \%)$ \\
\hline $100-149,000$ & $128(17.2 \%)$ & $10941(18.0 \%)$ \\
\hline$\geq 150,000$ & $75(10.1 \%)$ & $6179(10.2 \%)$ \\
\hline Missing & $181(24.4 \%)$ & $14671(24.1 \%)$ \\
\hline \multicolumn{3}{|l|}{ Age at menarche } \\
\hline$\leq 10$ & $71(9.6 \%)$ & $4471(7.4 \%)$ \\
\hline 11 & $134(18.0 \%)$ & $9846(16.2 \%)$ \\
\hline 12 & $201(27.0 \%)$ & $18534(30.5 \%)$ \\
\hline 13 & $204(27.5 \%)$ & $17050(28.0 \%)$ \\
\hline$\geq 14$ & $133(17.9 \%)$ & $10952(18.0 \%)$ \\
\hline Mean age at menarche (years) & $12.4(1.5)$ & $12.4(1.4)$ \\
\hline \multicolumn{3}{|c|}{ Menstrual cycle regularity-high school ${ }^{1}$} \\
\hline Very regular or regular & $530(71.3 \%)$ & $43458(71.4 \%)$ \\
\hline Usually irregular & $113(15.2 \%)$ & $9369(15.4 \%)$ \\
\hline Always irregular & $97(13.1 \%)$ & $7814(12.8 \%)$ \\
\hline No periods & $3(0.4 \%)$ & $212(0.4 \%)$ \\
\hline \multicolumn{3}{|l|}{ Time to cycle regularity } \\
\hline$<1$ year & $327(44.0 \%)$ & $28365(46.6 \%)$ \\
\hline $1-2$ years & $188(25.3 \%)$ & $15148(24.9 \%)$ \\
\hline $3-4$ years & $59(7.9 \%)$ & $4105(6.8 \%)$ \\
\hline $5+$ years or never & $169(22.8 \%)$ & $13235(21.8 \%)$ \\
\hline \multicolumn{3}{|l|}{ Cycle length ages 18-22 } \\
\hline$\leq 25$ days & $73(9.8 \%)$ & $6404(10.5 \%)$ \\
\hline 26-31 days & $492(66.2 \%)$ & $40405(66.4 \%)$ \\
\hline 32-39 days & $110(14.8 \%)$ & $9445(15.5 \%)$ \\
\hline $40+$ or irregular & $68(9.2 \%)$ & $4599(7.6 \%)$ \\
\hline
\end{tabular}




\begin{tabular}{lcc}
\hline Variable & $\begin{array}{c}\text { ASD mothers }(\boldsymbol{n}=\mathbf{7 4 3}) \\
\boldsymbol{n}(\boldsymbol{\%}) \text { or mean (std) }\end{array}$ & $\begin{array}{c}\text { Non-ASD mothers }(\boldsymbol{n}=\mathbf{6 0}, \mathbf{8 5 3}) \\
\boldsymbol{n}(\boldsymbol{\%}) \text { or mean (std) }\end{array}$ \\
\hline Mean age at first OC use (years) & $21.2(4.8)$ & $20.9(4.3)$ \\
Ever used OCs (through follow-up) & $640(86.1 \%)$ & $53785(88.4 \%)$ \\
Pre-gravid OC use & $598(80.5 \%)$ & $48212(79.2 \%)$ \\
Mean duration of pregravid OC use in years & $3.15(3.5)$ & $2.80(3.1)$ \\
Body shape at age $10^{2}$ & & \\
1 & $145(19.5 \%)$ & $11296(18.6 \%)$ \\
2 & $223(30.0 \%)$ & $19225(31.6 \%)$ \\
3 & $162(21.8 \%)$ & $14007(23.0 \%)$ \\
4 & $126(17.0 \%)$ & $9482(15.6 \%)$ \\
25 & $87(11.7 \%)$ & $6843(11.3 \%)$ \\
BMI at 18 & & $24568(40.4 \%)$ \\
$<20$ & $298(40.1 \%)$ & $19928(32.8 \%)$ \\
20 to $<22$ & $234(31.5 \%)$ & $11369(18.7 \%)$ \\
22 to $<25$ & $135(18.2 \%)$ & $4035(6.6 \%)$ \\
25 to $<30$ & $52(7.0 \%)$ & $953(1.6 \%)$ \\
$\geq 30$ & $24(3.2 \%)$ & $17056(18.2 \%)$ \\
BMI at baseline & & $6060(10.0 \%)$ \\
$<20$ & $127(17.1 \%)$ & \\
20 to $<22$ & $196(26.4 \%)$ & $(15.4 \%)$ \\
25 to $<25$ & $209(28.1 \%)$ & $(27.8 \%)$ \\
230 & $144(19.4 \%)$ & \\
\hline
\end{tabular}

$A S D$ autism spectrum disorder, $O C$ oral contraceptive, $B M I$ body mass index

1 regularity.

$2^{2}$ Categories according to diagram shown in Appendix 
Table 2

Maternal menstrual cycle characteristics, oral contraceptive use, BMI and body shape in relation to risk of $\operatorname{ASD}(N=61,596)$

\begin{tabular}{|c|c|c|c|c|}
\hline \multirow[t]{2}{*}{ Variable } & \multirow{2}{*}{$\begin{array}{l}\text { Crude } \\
\text { RR }\end{array}$} & \multirow{2}{*}{$\begin{array}{l}\text { Age-adjusted } \\
\text { RR }\end{array}$} & \multicolumn{2}{|l|}{ Fully-adjusted 1} \\
\hline & & & RR $(95 \%$ CI $)$ & $p$-value * \\
\hline \multicolumn{5}{|l|}{ Age at menarche } \\
\hline$\leq 10$ & 1.46 & 1.55 & $1.54(1.18,2.02)$ & 0.03 \\
\hline 11 & 1.25 & 1.28 & $1.27(1.03,1.58)$ & \\
\hline 12 & $1.0(\mathrm{ref})$ & 1.0 & 1.0 & \\
\hline 13 & 1.10 & 1.10 & $1.10(0.91,1.34)$ & \\
\hline$\geq 14$ & 1.12 & 1.08 & $1.08(0.87,1.34)$ & \\
\hline \multicolumn{5}{|c|}{ Menstrual cycle regularity in high school } \\
\hline Usually or always regular & $1.0(\mathrm{ref})$ & 1.0 & 1.0 & 0.81 \\
\hline Usually irregular & 0.99 & 0.96 & $0.97(0.79,1.19)$ & \\
\hline Always irregular & 1.02 & 1.00 & $1.03(0.83,1.28)$ & \\
\hline \multicolumn{5}{|l|}{ Time to cycle regularity } \\
\hline$<1$ year & 1.0 (ref) & 1.0 & 1.0 & 0.30 \\
\hline $1-2$ years & 1.08 & 1.04 & $1.04(0.87,1.24)$ & \\
\hline $3-4$ years & 1.24 & 1.13 & $1.15(0.87,1.51)$ & \\
\hline $5+$ years or never & 1.11 & 1.07 & $1.09(0.90,1.31)$ & \\
\hline \multicolumn{5}{|l|}{ Menstrual cycle length age $18-22$} \\
\hline ک25 days & $1.0(\mathrm{ref})$ & 1.0 & 1.0 & 0.11 \\
\hline 26-31 days & 0.94 & 0.91 & $0.91(0.71,1.16)$ & \\
\hline 32-39 days & 0.96 & 0.96 & $0.97(0.79,1.19)$ & \\
\hline $40+$ or irregular & 1.21 & 1.22 & $1.26(0.98,1.62)$ & \\
\hline OC use prior to 1 st pregnancy & 1.08 & 1.00 & $1.00(0.84,1.20)$ & 0.97 \\
\hline$\geq 3$ years pregravid $\mathrm{OC}$ use & 1.04 & 0.92 & $0.92(0.79,1.06)$ & 0.25 \\
\hline \multicolumn{5}{|l|}{ Body shape at age $10^{2}$} \\
\hline 1 & 1.11 & 1.18 & $1.18(0.96,1.45)$ & 0.76 \\
\hline 2 & 1.0 (ref) & 1.0 & 1.0 & \\
\hline 3 & 1.00 & 1.01 & $1.01(0.83,1.24)$ & \\
\hline 4 & 1.14 & 1.20 & $1.20(0.96,1.49)$ & \\
\hline 25 & 1.09 & 1.19 & $1.19(0.93,1.52)$ & \\
\hline \multicolumn{5}{|l|}{$\mathrm{BMI}$ at 18} \\
\hline$<20$ & 1.03 & 1.03 & $1.04(0.88,1.24)$ & $0.009^{\dagger}$ \\
\hline 20 to $<22$ & $1.0(\mathrm{ref})$ & 1.0 & 1.0 & \\
\hline 22 to $<25$ & 1.01 & 1.00 & $1.00(0.81,1.23)$ & \\
\hline 25 to $<30$ & 1.10 & 1.11 & $1.09(0.81,1.48)$ & \\
\hline$\geq 30$ & 2.12 & 2.08 & $2.03(1.34,3.08)$ & \\
\hline \multicolumn{5}{|l|}{ BMI at baseline } \\
\hline$<20$ & 1.13 & 0.99 & $1.01(0.81,1.26)$ & 0.33 \\
\hline 20 to $<22$ & 0.97 & 0.92 & $0.93(0.76,1.13)$ & \\
\hline
\end{tabular}




\begin{tabular}{|c|c|c|c|c|}
\hline \multirow[t]{2}{*}{ Variable } & \multirow{2}{*}{$\begin{array}{l}\text { Crude } \\
\text { RR }\end{array}$} & \multirow{2}{*}{$\begin{array}{l}\text { Age-adjusted } \\
\text { RR }\end{array}$} & \multicolumn{2}{|l|}{$\underline{\text { Fully-adjusted } 1}$} \\
\hline & & & $\mathbf{R R}(95 \% \mathbf{C I})$ & $p$-value * \\
\hline 22 to $<25$ & $1.0(\mathrm{ref})$ & 1.0 & 1.0 & \\
\hline 25 to $<30$ & 1.08 & 1.14 & $1.13(0.91,1.39)$ & \\
\hline$\geq 30$ & 0.92 & 1.04 & $1.02(0.78,1.35)$ & \\
\hline
\end{tabular}

Risk ratios and their $95 \%$ confidence intervals are shown. Bolded values indicate significance

1 Fully adjusted models included age at baseline, race, income; BMI, body shape at age 20, and cycle length and regularity models also included age at menarche.

2 Median category used as the referent for body shape model

* $p$-value is the trend test $p$-value for all variables except the binary ones or unless otherwise indicated. The trend test $p$-value is replaced with the $p$ value for the test for overall significance of the curve when significant non-linearity of the association was evident. For significant individual categories, individual $p$-values are provided in the text.

${ }^{\dagger} p$ for overall significance of the curve; $p$ for non-linearity for BMI at 18 was 0.008 


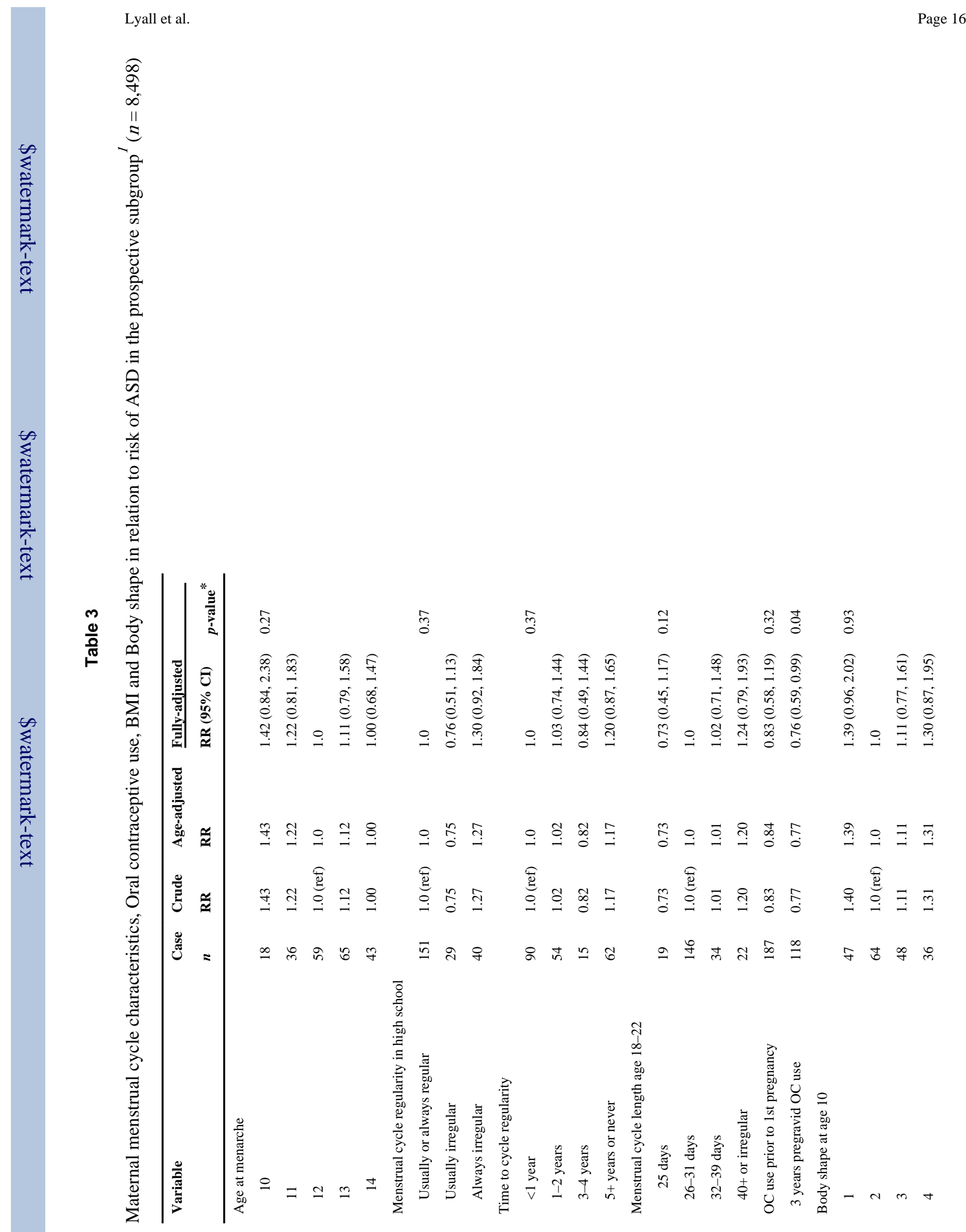

J Autism Dev Disord. Author manuscript; available in PMC 2012 November 09. 


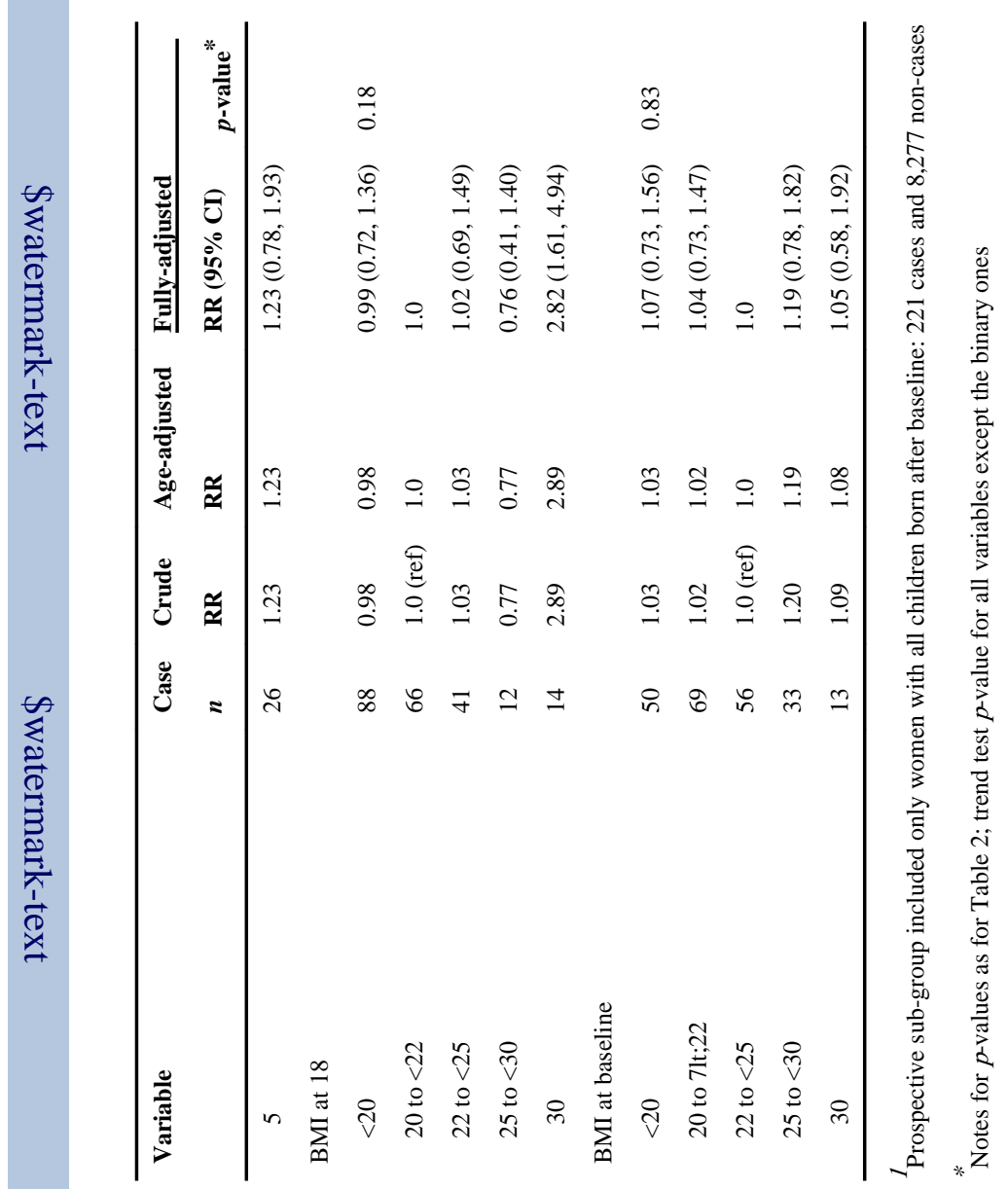

